\title{
Predictive Value
}

National Cancer Institute

\section{Source}

National Cancer Institute. Predictive Value. NCI Thesaurus. Code C16238.

An expression of the likelihood that a given test result correlates with the presence or absence of disease. 